\section{Human immunology}

Immunology of Human Reproduction. Edited by J. S. Scott and W. R. Jones. Pp. xviii + 476. (Academic: London; Grune and Stratton: New York, 1976.) $£ 15$.

THIS is a fascinating book for all those who have an interest in immunology and development. The book begins with a glossary and a primer of immunology that has freed later chapters from the need to define and explain. This introductory section is oversimplified in places and occasionally patronising, but these faults are outweighed by the good it does in summarising and ordering a field overgrown with observations and special terminology.

Although no formal break is made, I would divide the remaining chapters into two sections: chapters 2-6 dealing with basic aspects of immunology in development, and drawing on both clinical material and animal, model, experiments; and chapters 7-13, dealing largely with clinical aspects of human immunology and development. The chapters are of varied length, quality and distance from the stated topic of the book, but they all elaborate their topics in considerable detail, and it is this detail that is the book's strength.

The authors themselves are often moved by the complexities and uncertainties of the topics, to use phrases like "the tip of the iceberg of confusion" or to make statements such as "existing knowledge concerning the role of immunological factors in gestosis is fragmentary ..." or "the picture ... as in so many areas of reproductive immunology is confused ..."This confusion is, however, the result of contradictory or insufficient clinical and experimental observations, and by detailing these the authors have done a great service, allowing others to speculate on, and experiment over, the data presented here.

The fields of immunology and reproduction are connected at many points. Chapter 2 , by $\mathbf{M}$. H. Johnson, makes a connection between the two by discussing the stages of early mammalian development (exemplified by the mouse embryo) and some ways in which immunological techniques may be used to characterise these stages. In this chapter the problem is raised of the maternal immune response to antigens of the embryo, either to alloantigens, or to stage-specific antigens. This problem, still unsolved, is reiterated in later chapters, notably that by Billington on the immunology of trophoblast, and in a chapter by Medenhall, which considers all aspects of maternal-foetal immunology, transfers of maternal im- munoglobulins and cells, and the problem of the foetal allograft. A further comment on the problem is made by Gusdon, in a chapter on the effects of pregnancy on all maternal immune responses. The first section closes with a chapter by W. Jones on the phylogeny and ontogeny of the immune response. This chapter considers development of foetal immune responses in its own right. It is perhaps too broad and contains a few notable factual errors (the mouse is assigned a $30-d$, not a $20-d$ gestation period), but the section on the maturation of the immune responses of the human foetus is thorough, including the immunological aspects of breast feeding, and quite interesting.

In the second section we are given extended treatments of particular topics. Some, such as that of chapter 7 on the consequences of maternal infection for the foetus, cut across the divisions set up in the earlier chapters. Others, such as a chapter on the effect of pregnancy on immunological diseases of the mother, analyse a limited topic within the larger one already set. Maternal-foetal immunological interactions are prominent in $\mathbf{R h}$ disease, and this topic receives full treatment in a chapter which emphasises clinical aspects of the disease, although failing to discuss the molecular aspects of $R h$ antigens and of the transfer of $R h$ antibodies across the placenta. Gestosis

\section{Volcanic picture book}

Volcanoes and Impact Craters on the Moon and Mars. Pp. 463. By P. Leonardi. (Elsevier Scientific: Amsterdam and NewYork, 1976.) Dfl.166; \$59.75.

AT a first glance this book is very impressive; it is beautifully presented and contains large numbers of high quality pictures, both in colour and in blackand-white. For a subject which relies much on interpretation of photographs taken of other planets, this is highly commendable. The author has not only reproduced the standard NASA and Soviet pictures taken from spacecraft but has also included many extremely interesting pictures of geological phenomena on Earth.

Although the book was originally written in Italian it has generally speaking been well translated into English and reads easily. The author has obviously read widely around this subject and there can be few planetary scientists who will be disappointed at not finding their name in the index. (eclampsia/preclampsia), a condition involving the immune response in some obscure manner is also given a chapter of its own. If we are not convinced at the end of this chapter that the condition is due to immune responses, neither are we put off further exploration of the problem. Similarly, the role of the immune system and of cell surface antigens is unclear in cases of trophoblastic neoplasms. Again, the question cannot be answered but it is well set out and elaborated. Other chapters cover non-gestational reproductive tract neoplasms, and immunological aspects of infertility as well as the prospects for immunology in the control of fertility. All of the chapters carry long lists of references: the average is about 130; and one chapter, that by Edwards on immunology and fertility control contains 390 .

The immunology of reproduction is a vast subject and, as will be seen from the individual subjects mentioned, may be taken in many senses. It would be too much to expect a consistent exposition of the subject; indeed, such an exposition would certainly be highly biased, if not false. The opposite approach taken here, if it occasionally daunts the authors, stimulates their readers.

Michael Edidin

Michael Edidin is Professor of Biology at Johns Hopkins University, Baltimore, Maryland.

In view of these comments the reviewer would have liked to have recommended this book. But although pictorially the book is very much upto-date (even containing Viking pictures), many of the ideas expressed in the text are reiterations of ideas current among some scientists in this field more than ten years ago, before spacecraft exploration of the Moon and planets. Much of the book is devoted to the old argument of impact as against volcanic craters on the Moon, and although the author presents the 'impactists' case fairly, his conclusions lie well within the "volcanic' camp and would not be accepted by most planetary workers who have studied the evidence obtained during the past ten years.

Sadly, although recommended for its presentation and picture quality, this book will be of little interest to scientists in the field and can only be recommended to students for the historical interest of the text.

\section{J. E. Guest}

J. E. Guest is Lecturer in the Department of Physics and Astronomy at University College, London, UK. 